Narrar ESI en pandemia. Cuando el relato se transforma en acción

María Susana Felli

Question/Cuestión, Nro.70, Vol.3, diciembre 2021

ISSN: 1669-6581

URL de la Revista: https://perio.unlp.edu.ar/ojs/index.php/question/

IICom -FPyCS -UNLP

DOI: https//doi.org/10.24215/16696581e623

\title{
Narrar ESI en pandemia
}

\section{Cuando el relato se transforma en acción}

\author{
Narrating ESI in a pandemic \\ When history turns into action
}

\section{María Susana Felli}

Facultad de Periodismo y Comunicación Social, Universidad Nacional de La Plata

Argentina susanafelli@gmail.com

"Tú me quieres alba, me quieres de espumas, me quieres de nácar. (...)" Alfonsina Storni, argentina, 1892-1938

"Tú me quieres blanca" 


\section{Resumen}

El presente trabajo establece un aporte para la proyección de la Educación Sexual Integral en el sistema educativo. "Narrar la ESI en pandemia: cuando el relato se transforma en acción" tiene como objetivo, entre otros, la propuesta de reflexionar sobre las mujeres y las conquistas de derechos. La invitación es trabajar en la deconstrucción de las ideas hegemónicas. En este sentido, toman importancia algunas experiencias vinculadas con las políticas públicas, las articulaciones con los espacios de práctica docente y los programas socioeducativos.

Además, es fundamental hacer notar que el contexto en el que se sitúa el artículo, trabaja en particular con los protagonistas del sistema educativo formal que, a la luz del ASPO, se configuran en sujetos que actúan para moldear sus propias prácticas.

En primera instancia, el trabajo contiene las argumentaciones necesarias para dejar en claro cuáles son aquellas epistemologías feministas que nos fundamentan como mujeres de pensamiento, debate y construcción de sentido.

En segunda instancia, se trabajará la perspectiva de investigación narrativa en relación con la experiencia. De este modo, se presentan relatos de experiencias que dan lugar a saberes que de otro modo se encuentran invisibilizados en lo institucional y en el discurso hegemónico social.

Palabras clave: ESI; educación; narrativas; pandemia

\section{Abstract}

The present work establishes a contribution for the projection of the Integral Sexual Education in the educational system. "Narrating CSE in a pandemic: when the story is transformed into action" has as its objective, among others, the proposal to reflect on women and the conquests of rights. The invitation is to work on the deconstruction of hegemonic ideas. In this sense, some experiences related to public policies, articulations with teaching practice spaces and socio-educational programs take on importance.

\footnotetext{
IICom (Instituto de Investigaciones en Comunicación)

Facultad de Periodismo y Comunicación Social

Universidad Nacional de La Plata
} 
In addition, it is essential to note that the context in which the article is situated works in particular with the protagonists of the formal educational system who, in the light of the ASPO, are configured into subjects who act to shape their own practices.

In the first instance, the work contains the necessary arguments to make clear which are those feminist epistemologies that base us as women of thought, debate and construction of meaning.

In the second instance, the narrative research perspective will be worked on in relation to the experience. In this sense, accounts of experiences are presented that give rise to knowledge that is otherwise invisible in the institutional and in the social hegemonic discourse.

\section{Encontrar(nos) en igualdad}

Hablemos de la ESI, Educación Sexual Integral. Las primeras voces resonantes y disidentes fueron "de eso no se habla", "a mis hijxs les enseño yo", "no tiene que haber educación sexual en las escuelas". Los tiempos corrieron, la educación adoptó la ESI cada vez más acorde a las nuevas perspectivas. Fue promulgada como ley en Argentina, bastante resistida aún hoy por sus contenidos y porque viene a romper con antiguos estereotipos. Además, porque todavía hay un profundo desconocimiento acerca de lo que abarca la ESI en la formación integral de las personas.

La ESI es una Ley, la 26150, sancionada el 4 de octubre de 2006 (ver ANEXO). Contempla su implementación desde el Nivel inicial hasta el Nivel Superior educativo. Todas las escuelas del país trabajan la ESI. Como tal, es un derecho de las familias y de Ixs adolescentes y jóvenes. En el año 2008 salieron los Lineamientos Curriculares Federales de ESI obligatorios para todos los niveles y estudiantes del país. Posteriormente, la resolución 340/18 agrega algunos contenidos y enfoques.

La ESI trabaja numerosos contenidos porque cada eje se despliega y repliega en tantos otrxs: el cuidado del cuerpo, el reconocimiento de la perspectiva de género, el respeto por la diversidad, la valoración de la afectividad, el ejercicio de los derechos, mujeres y 
derechos, trata de personas, violencia de género, interrupción voluntaria del embarazo, identidad de género y diversidad sexual, etc.

Según Graciela Morgade, investigadora de la Universidad de Buenos Aires,

"No se trata solamente de estudiar las peculiaridades que cada grupo de sexo -género, edad, generación, etc.- pueda desarrollar. Al introducir la noción de "desigualdad", la perspectiva de género, acompañada posteriormente por los estudios de la homosexualidad y los más recientes de la teoría queer, se está trabajando también sobre las relaciones de poder que la construcción social de la sexualidad implica. Esto lleva a analizar los modos en que operan los prejuicios sociales acerca de lo "adecuado" o no para que las mujeres sean "femeninas" y que los varones sean "masculinos". La coerción sexual, los mitos con respecto a la sexualidad, los temores a concurrir a los servicios de salud, el desconocimiento del propio cuerpo, y tantas otras limitaciones que sufren las personas a lo largo de su vida, tienen sus raíces en la sociedad y no solamente en la constitución subjetiva individual." (Morgade, 2006: $6)$.

Partimos de la conceptualización de "género" como una construcción cultural, y por consiguiente, construcción política ya que el sistema de ideas y creencias en los que estamos inmersos no son ajenos a nuestras representaciones, discursos y/o acciones. Además, se percibe en el concepto de género un anclaje de interpretante e interpretado, es decir desde qué posicionamientos se enuncia y se escucha para luego reproducirse. Por este motivo, se relaciona el género con medios de comunicación, academia, industria cultural, arte y politicidad, entre otros aspectos.

En el presente artículo la propuesta es centrarnos en las mujeres y la conquista de derechos, eje temático que se vincula muy estrechamente con planteos posteriores. Además, se incorporan dos narrativas personales de experiencias pedagógicas que tuvieron como protagonista la ESI y el eje temático mencionado, desarrolladas en el del Nivel Inicial y Nivel Secundario educativos. Se trata, por un lado, del Proyecto "La gran pregunta. El desafío de buscar en igualdad", llevado a cabo por la Profesora Mariela Padula y sus colegas durante el año 2020 y anteriores en la Ciudad Autónoma de Buenos Aires, Argentina. Por otra parte, el Proyecto “¿Dónde está mi ESI? Los derechos de los y las estudiantes”, coordinado por la 
Profesora Andrea Beratz y diez estudiantxs de la Escuela Secundaria No 14 Carlos Vergara de la Ciudad de La Plata, Provincia de Buenos Aires, Argentina, durante el año 2020 y anteriores.

\section{Pensar derechos de las mujeres}

La perspectiva de género es una construcción social y cultural, como la identidad. Se configura en la conjunción de lo histórico-social-ideológico-económico. Hay una idea hegemónica de cómo ser masculino o femenino, mediada por la publicidad, como "modelos" de ser varón y de ser mujer. Esos modelos redundan en la división del trabajo y en proyectos económicos. Por eso, la invitación necesaria es a desarmar o deconstruir para ser más justxs e igualitarixs.

Una perspectiva de género se construye,también, desde el 8M: 8 de Marzo, Día de las Mujeres. Los proyectos de ESI que se relacionan con derechos de las mujeres deberían comenzar por el 8M y sus significaciones. Es un día de lucha. Por eso, el lema convocante del último 8M fue: "No me regales flores" y se declaró paro mundial de mujeres a raíz de los crecientes femicidios. El paro internacional de mujeres fue creado por un movimiento feminista en Polonia, durante 2016, y se viene replicando anualmente. Los medios de comunicación, algunos más que otros en posturas contrarias, contribuyeron a armar estos horizontes de sentido. Luciana Peker, periodista y escritora, viene trabajando y accionando el feminismo. En sus estudios, explicita lo que llamó "la revolución de las hijas". Es decir, una movida que se ha denominado como "Cuarta Ola" del feminismo en Argentina y "ha tenido sin dudas una fuerte impronta en diversas expresiones del movimiento de mujeres/feminismos desde 2015 a esta parte: nuevas formas de comunicación, ingreso masivo de adolescentes y pibas al movimiento y crecimiento exponencial de colectivos." (Fernández Hasan, 2019: 56).

En este sentido, parafraseando el libro-álbum "La gran pregunta" de Wolf Erlbruch, el gran grito "Para qué estoy aquî" formulado como pregunta existencial deviene en una aserción: "Ni Una menos". La lucha de la mujeres tras este grito es una manifestación transformada en colectivo de repercusión nacional, convocada a raíz del femicidio de una adolescente embarazada en Rufino, Provincia de Santa Fe, y el de otra mujer asesinada por su expareja en el barrio de Caballito, Provincia de Buenos Aires. Se convocó a una marcha de repudio a 
través de las redes sociales para el de 3 de junio de 2015, fundamentalmente en la Plaza del Congreso. Fue una convocatoria espontánea y se viralizó con límites insospechados, a los que se sumaron personalidades de diferentes sectores: actrices, escritoras, periodistas, y familiares de víctimas de violencia de género. Así comenzó a delinearse un colectivo que aporta toda una carga de sentidos a las luchas feministas en nuestro país.

Otro aspecto a destacar son los Encuentros Nacionales de Mujeres. El último, en 2019, se realizó en mi ciudad, La Plata, y albergó a centenares de mujeres de todas las provincias y países limítrofes. Cada encuentro deja unos manifiestos y numerosas producciones colectivas para llevar al Ministerio de la Mujer, en primera instancia, tanto al Ministerio Provincial como al Nacional. Los encuentros se crearon en 1985, cuando un grupo de mujeres argentinas estuvo participando en la clausura de la Década de la Mujer en Kenia. Los encuentros tienen una modalidad única: autoconvocado, horizontal, federal, autofinanciado, plural y democrático (Beratz, 2020: 35).

Continuando con las argumentaciones, se habla de epistemologías feministas con la insoslayable premisa de que son las mujeres las que dicen, piensan, construyen sentidos, y no son dichas o pensadas desde "espacios androcéntricos" de construcción del conocimiento . Tal es el caso de las universidades, como señala Diana Maffía, donde aún hoy no se han sedimentado o, lo que es peor, no se han legitimado como tal las epistemologías feministas. Hay una brecha entre el decir y el actuar, todo queda en teorías pero las prácticas continúan siendo muy sesgadas.

Para agrietar o quebrar ese "conocimiento androcéntrico" que circula en la academia deberían reverse las perspectivas desde las cuales se construyen los saberes en las distintas áreas. Un ejemplo de esto son algunos de programas de cátedras, desde donde se podría analizar cuáles son los nodos de pensamiento prevalentes según momentos, posicionamientos, ideología.

El problema, siguiendo a Maffía, es que las epistemologías feministas están vistas como una ideología o crítica social por fuera de los métodos legitimados por la ciencia misma para evaluar conocimiento. Entonces, es imprescindible continuar desarrollando ciencia que ponga a las mujeres como sujetxs de conocimiento y como sujetxs de enunciación. Los 
"grandes relatos" dejaron huellas en la construcción de metáforas no neutrales ni carentes de la marca del feminismo político como hito de los años 70 .

Coincido con Marisa Ruiz Trejo en que debemos mirar las epistemologías en clave de lo alternativo, lo popular, lo que "está por fuera", por las condiciones en las que se producen estos pensamientos: "El punto de enunciación, en gran medida popular, es alternativo al de las teorías que han surgido en otros espacios por las condiciones materiales en las que se han producido estos pensamientos y por el contexto social, que no es ajeno a las comunidades científicas y a las comunidades epistémicas que los han producido" (Ruiz Trejo, 2016: 30).

En mi tarea con narrativas de experiencias pedagógicas esto es fundamental, ya que Ixs sujetxs que enuncian, docentes, estudiantes, actorxs escolares, educadoras populares, comienzan a visibilizar el saber pedagógico legitimado a través de sus escritos. Los "sin nombre" pasan a ser autorxs de sus relatos y son publicados en revistas especializadas. Muy similar a lo que sucede cuando son las mujeres las invisibilizadas. Por algo la educación estuvo años a cargo de las mujeres, como mano de obra barata, las "segundas madres" o "maestras tías" al decir de Paulo Freire. Esa es mi propuesta, la de visibilizar, dar la palabra, hacer circular, mostrar para configurar y constituir unas epistemologías feministas que tomen en cuenta las distintas voces, muchas veces acalladas, no sólo de aquellas que resuenan en algunos ámbitos.

\section{Relatos de experiencias}

\section{Desandar las desigualdades}

Llegué a este libro porque escribí unos artículos para la editorial Noveduc, Novedades Educativas. Creo que me impresionó más al ver que era una experiencia coordinada por una colega profesora de La Plata, desde el área de Lengua y Literatura. Hizo mucho ruido en mí querer saber qué cuentos, qué aspectos, qué contenidos son de interés para adolescentes de mi propia ciudad. Estamos en el día 10 de julio de 2020. Un libro "recién salido del horno", como refiere el dicho. 
Entonces, en plena pandemia por COVID-19, en el marco del ASPO (aislamiento social preventivo y obligatorio, me dispuse a leer dos "novedades" editoriales de este cuatrimestre. Me encuentro con “¿Dónde está mi ESI? Un derecho de los y las estudiantes”, el libro en cuestión, y "Mientras respiramos (en la incertidumbre)" del educador Carlos Skliar. Propuestas atrayentes y buenas compañías. Bálsamo para estos más de 120 días que llevamos adentro de casa. Afuera, el enemigo acechante.

Atrapada en la lectura descubro que la experiencia de mi colega, Andrea Beratz, y de sus estudiantxs estuvo auspiciada por el Programa Jóvenes y Memoria dependiente de la Comisión Provincial por la Memoria. Celebro enormemente que sea así. Los jóvenes y su compromiso. De eso se trata, de promoverlxs en su mejor "versión".

También festejo la convocatoria de un prólogo de Susy Shock, actriz, escritora, cantante y docente argentina. Como ella se autodenomina: una "artista trans sudaca". Hago eco de las palabras del prólogo de Susy: "No puedo dejar de soñar escuelas nuevas con docencia trava trans en la que hagamos libros junto a adolescencia trava trans para dar cuenta antropológicamente de una época de heterosexualidad obligatoria, disciplinadora y violenta, ya perimida, y publicar junto a la academia (llena de travas trans esta vez) un dossier y toda una bibliografía sobre la belleza de ser por fin un mundo trava trans.” (Beratz, 2020:11).

Creo que con estas líneas del prólogo es posible poner en diálogo a Paul Preciado y el relato de Agnés, por su mirada de las "tecnologías del cuerpo" como espacios donde se saldan las contradicciones biopolíticas, incluso muy medicalizadas, para reflexionar sobre los cuerpos:

"El relato de Agnès sólo tiene sentido a través del análisis de los procesos biotecnológicos de inscripción corporal que permitirán que su imitación de la intersexualidad pase por natural. No se trata simplemente de señalar el carácter construido del género, sino ante todo de reclamar la posibilidad de intervenir en esa construcción al punto de crear las formas de representación somáticas que pasarán por naturales. No obstante, el desplazamiento que emprendo con Agnès no debe interpretarse como una ruptura con el marco de anális butleriano, sino como un aporte a lo que la propia Butler llama, sin dar demasiados detalles, una consideración escenográfica y topográfica de la construcción del sexo (Butler, 2002). De ahora en más, y siguiendo a Teresa de Lauretis, hablaré sobre todo de 
las "tecnologías del género" como de un circuito complejo de cuerpos, técnicas y signos que comprenden no sólo las técnicas performativas, sino también técnicas biotecnológicas, cinematográficas, cibernéticas, etc. (De Lauretis, 1987). (Preciado, 2007:6).

Por otra parte (o por la misma), la tapa del libro es una muestra de la fuerza connotativa y de construcción de sentidos que tienen las imágenes y el diseño. Veo el verde de los pañuelos que caracteriza la "marea verde" feminista, como símbolo de la protesta a favor de la despenalización del aborto. Veo el blanco de los pañuelos de las Madres de Plaza de Mayo. Veo noticias de los medios de comunicación. Sobre la Ley de Matrimonio Igualitario, por ejemplo.

Veo, además, dos fotos de Diana Sacayán, asesinada en 2015. Diana fue reconocida como una de las principales activistas del movimiento de derechos humanos y de la lucha por el reconocimiento y la inclusión social del colectivo travesti en Argentina y en Latinoamérica. Veo a la joven de 23 años Johana Ramallo, platense desaparecida en 2017. Hallaron parte de sus restos en 2018. Se cree que fue prostituida y descuartizada. Veo el nombre de Sandra Ayala Gamboa, desaparecida, violada y asesinada hace 13 años en La Plata. Los casos todavía impunes. Femicidios y travesticidios. "Ni una menos", ese es el grito.

Qué más ver. Se me anuda la garganta y mis ojos se cargan con lágrimas. Lloro la rabia, la vergüenza, la injusticia. Lloro con otrxs que lloran sus muertes. Lloro la vida y sus desventuras. Somos muchxs, somos juntxs transformando el llanto en acción, en sororidad, en cercanías, en ternura y abrazos.

Recuerdo una frase de la investigadora feminista argentina Rita Segato que varias veces se sacó de contexto: "Que la mujer del futuro, no sea el hombre que estamos dejando atrás". En un mundo desigual, con una pandemia desigual, con políticas económicas desiguales en países que padecen desigualdades, las mujeres tenemos un legado: actuar para desandar. En eso estamos. Desandar lo andado para reconstruir unas sociedades más justas e igualitarias.

\section{Adentro es un mundo}


Espero unos minutos, siempre espero. Son las $16 \mathrm{hs}$. de un helado viernes platense. "Quedate en casa", dice la propaganda. Es tiempo de ASPO, aislamiento social preventivo y obligatorio. Porque el enemigo, el virus COVID-19, acecha. Viernes 17 de Julio de 2020. Ya es hora, diez minutos tarde. Me conecto a Zoom.

De "el otro lado", varios rostros atentos y una voz peculiar me recuerda mi maestra de jardín, una voz de flauta dulce, cascabeles y "toc toc" de los jardines de infantes. "Me presento. Soy Mariela Padula. Maru.". Una maestra de Jardín de Infantes va hablar de la ESI en el nivel. "Qué interesante" "A ver qué propone, que no se haya dicho ya". Y me quedo, entre asombrada y absorta por lo que voy escuchando. Mujeres. Mujeres fuertes. Maestras que con su experiencia en educación proyectaron visibilizar otras mujeres de nuestra historia. Así escucho, veo, leo a Juana Arzuduy, María Remedios del Valle, Rosa Guarú, Pancha Hernández, Juana Manso, Bartolina Sisa. Somos muchas, somos tantas, somos juntas. Y estamos, estamos al fin del comienzo, en páginas de historia recobrada, de años de postergación y silencios, de acallar, de borramientos.

Traigo unos versos de Alejandra Pizarnik que siempre cito: "Una mirada desde la alcantarilla/ puede ser una visión del mundo/ la rebelión consiste en mirar una rosa/hasta pulverizarse los ojos". Pienso que la experiencia de Maru y sus niñxs son una mirada desde la alcantarilla. Ese lugar o espacio del olvido que una mirada androcéntrica del mundo creó para la historia. Entonces, no puedo dejar de pensar en un seminario que curso, "Género y desigualdades", y tantos temas/problema que puedo vincular a mi narrativa. Entre ellos, una cita de Morton en el texto de Olivera sobre la opresión femenina:

"Este último nivel de la explotación capitalista -la del hombre sobre la mujer- que aquí llamamos opresión femenina para distinguirla de su explotación como trabajadora, solo muy excepcionalmente se ha tomado en consideración como parte de los mecanismos de explotación económica del sistema, y a nuestro juicio es un pilar no solo muy importante sino indispensable para su funcionamiento que debe analizarse con mucha profundidad, para buscarle solución y lograr realmente la liberación íntegra de la mujer; pues si no se cambian las raíces estructurales de su explotación, la misma mujer seguirá ayudando a reproducir el sistema. La opresión de la mujer se da básicamente en el marco institucional de la familia, el 
sistema capitalista la ha destinado inexorablemente y casi exclusivamente a la producción y mantenimiento de la fuerza de trabajo que el capitalismo necesita para su propia reproducción y expansión; por ello las ocupaciones fundamentales e inevitables de las mujeres en nuestro sistema son "las labores domésticas" (Morton, 1974, p. 8)". (Olivera, 2019: 195).

Pienso en la vigencia del escrito, en la educación argentina desigual para las mujeres. Las docentes somos en su mayoría mujeres. Los salarios son bajos en relación a otros ámbitos laborales, de tradición "mano de obra barata". Viene de una larga tradición, además, de la "señorita maestra". Aún hoy vivimos sojuzgadas a una sociedad y una educación que sigue siendo vertical, patriarcal y desigual. Me viene como inspiración un escrito, un contrato que circula en las aulas hoy para reflexionar sobre las prácticas docentes en perspectiva sociohistórico-política: el Contrato del Consejo Nacional de Educación a las Señoritas Maestras, de 1923 durante la presidencia de Alvear (ver ANEXO).

Asimismo, me replanteo mis propias prácticas del oficio docente, de la formación docente en Comunicación. Creo que tenemos mucho que mirar a otros niveles educativos. Todavía en Educación Superior falta desandar para rearmar desde lo pedagógico. Mi especialidad, las narrativas de experiencias, lo van a permitir. Los relatos como metáforas de resistencia donde el saber pedagógico, por fuera de los saberes establecidos y legitimados en la academia, suturan las prácticas del oficio. Me entusiasma reflexionar sobre estas prácticas como legado, como herencia a lo venidero, a los tiempos y a la "nueva normalidad" después de estos momentos tan devastadores e inciertos, por un lado, pero tan profundos, por otro, a la hora de dimensionar formas y maneras. Nueva domesticidad, nueva culturalidad, nueva sociabilidad, nueva educación (y actualizar formas que ya estaban dadas) y nuevos feminismos, por qué no.

Hacia unx mismx y con otrxs, toda crisis es un legado. Para que el mundo sea más humano, para salir del odio o del horror, para promover la igualdad y la fraternidad entre las personas. Nos lo debemos. Transitemos, sin reparos, hacia esos extensos horizontes.

\section{El final del comienzo}

Todo trabajo conlleva un apartado de conclusión y muchas veces esas conclusiones son un capítulo aparte o se ven forzadas en el contexto. 
Cito un fragmento de una carta a Gloria Anzaldúa, como condensación de varias tensiones que este artículo pretende presentar y saldar: "Este mensaje, que intenta ser para generaciones futuras es un grito de los desigual, de lo otre, de lo olvidado y ninguneado por generaciones hacia una simiente nueva de mirada soberana y emancipadora, donde lo distinto pueda encontrarse y tenga lugar porque es nuestrx, porque es logro, porque vos, porque importa.

Te dejo este regalo para que gritemos juntas, para que nos reconozcamos en las luchas de tantas compañeras que están en tantos espacios militando por un nuevo mundo de mayor humanidad. Boaventura de Sousa Santos nos habla de la cruel pedagogía del virus. Creo que también es cruel toda pedagogía del espanto. Del dolor y de sufrir muchas veces no se habla. Para que lo gritemos esta vez, va este manifiesto". (Felli, 2020).

Somos lo que otrxs callan. Sin dudas, somos colectivamente. Este recorrido formativo, este escrito en tiempos inciertos de pandemia, es el final de un comienzo. En verdad, nos llevamos puesto todo este tiempo que fue el encierro por COVID-19 transformado en una bitácora de viaje. El viaje ya comenzó. Sigamos, tanteando a veces, pero sigamos juntxs.

\section{Referencias bibliograficas}

Beratz, A.N (coord.) (2020). ¿Dónde está mi ESI? Un derecho de los y las estudiantes. La Plata: Comisión Provincial por la Memoria/NOVEDUC.

Elbruch, W. (2016) La gran pregunta. CABA: Libros del zorro rojo.

Fernández Hasan, V. (2019) "Narrativas feministas en los medios: notas acerca de la construcción de los temas de agenda del movimiento a través de los discursos de académicas y activistas". Boletín GEC $\mathrm{N}^{\circ}$ 23, junio 2019, 53-76. Disponible en https://dialnet.unirioja.es/servlet/autor?codigo=2123796. Consultado 20/7/2020.

García Suárez, C. I. (2001) La pedagogía del cuerpo como bastión del género. Nómadas (Col), № 14, abril 2001, Universidad Central Bogotá, Colombia, pp. 124-139. 
Greco, B. (2007) "Sexualidad, adolescencias y escuelas. Una perspectiva institucional". En Clement, A. (dir.). Educación sexual en la escuela. Perspectivas y reflexiones, Buenos Aires, GCBA, pp. 69-87.

Hernández, A. y Reybet, C.(2006) "Acerca de masculinidades, feminidades y poder en la escuela". Anales de la educación común, Tercer siglo / año 2 / № 4 / Filosofía política del currículum / agosto de 2006, Dirección General de Cultura y Educación de la Provincia de Buenos Aires, Dirección Provincial de Planeamiento.

Larguía, Isabel \& Dumoulin, John (1976). Hacia una ciencia de la liberación de la mujer. Barcelona: Editorial Anagrama, 8-17.

Larralde, G. (2019) Diversidad y género en la escuela. CABA: Paidós.

Maffía, D. (2007). Epistemología feminista: La subversión semiótica de las mujeres en la ciencia. Revista Venezolana de Estudios de la Mujer, 12, (28), 63-98. Disponible en:

$<$ http://www.rimaweb.com.ar/wp-content/uploads/2012/07/Rev-28-063-092.pdf > [Consulta: 21 abril 2020]

Molina, G. y Maldonado, M. (2011) "Interpelaciones a la escuela desde sexualidades diferentes. Notas etnográficas con estudiantes secundarios", En: Milstein, D. (comp), Encuentros etnográficos con niñ@s y adolescentes, Buenos Aires: Miño y Dávila, 2011.

Morgade, G. (2006), "Educación en la sexualidad desde el enfoque de género. Una antigua deuda de la escuela". En Novedades educativas, № 184.

Olivera Bustamante, M. (1979/2019) Consideraciones sobre la opresión femenina como una categoría para el análisis socioeconómico. En: Mercedes Olivera. Feminismo popular y revolución. Entre la militancia y la antropología, Basail Rodríguez, A. y Bosch Heras, M. (coords.), Buenos Aires: CLACSO, [parte 2, primeros textos feministas], 189-204. Disponible en: < http://biblioteca.clacso.edu.ar/clacso/se/20191205112859/Mercedes-Olivera-AntologiaEsencial.pdf > [Consulta: 21 abril 2020] 
Preciado, P. (2007) Biopolítica del género. En: Biopolítica, VV. AA., Buenos Aires: Ají de Pollo, 1-9. Disponible en: $<$ http://capacitacioncontinua.sociales.uba.ar/wpcontent/uploads/sites/25/2016/10/PRECIADO-Biopolitica-del-genero.pdf > [Consulta: 21 abril 2020]

Ruiz Trejo, M. (2016) "Aproximaciones a los estudios críticos feministas en México y Centroamérica". Clepsydra: Revista de Estudios de Género y Teoría Feminista, 15, 11-33. Disponible en: $<$ https://riull.ull.es/xmlui/bitstream/handle/915/6308/CL $15 \% 282016 \% 29$ 01.pdf?sequence=2 \&isAllowed $=y>$ [Consulta: 21 abril 2020]

Ruiz Trejo, M. y García Dauder, D. (2018) Los talleres "epistémico-corporales" como herramientas reflexivas para la práctica etnográfica. Revista Universitas Humanistica. Pontífica Universidad Javeriana. Facultad de Ciencias Sociales, 85. Disponible en: https://revistas.javeriana.edu.co/index.php/univhumanistica/article/view/24561 